\title{
Pemanfaatan Atribut Agama Terhadap Brand Image Blessed Brothers Café
}

\author{
Gary Dwiputra Liawijaya, Ahmad Junaidi,. \\ garydl241@gmail.com.ahmadjunaidi@untar.ac.id \\ Fakultas Ilmu Komunikasi Universitas Tarumanagara
}

\begin{abstract}
Today, various business ventures carried out have experienced extraordinary developments in terms of concept and marketing, of course. Blessed Brothers Cafe as a cafe that includes start up by carrying out a spiritual concept related to Christianity and utilizing religious attributes as a decoration for the cafe. Blessed Brothers Cafe in developing its business does not necessarily seek profit but through their vision and mission that prioritizes the best service and experience so that the name of Jesus is elevated and makes the Blessed Brothers Cafe as a place to share together alias evangelism, making the cafe include in a unique category in terms of concept and vision and mission. The purpose of this study was to find out the brand image of the Blessed Brothers Cafe as a unique start up cafe based on the concept of utilizing Christian religious attributes and referring to the cafe's vision and mission. The theory used in this study includes the types of branding theory such as brand image theory and brand association and attribute theory. The research method used in this study is a qualitative descriptive research method. Data collection is done by interview, observation, and documentation. Through the results of the study, the researchers concluded that he Blessed Brothers Cafe brand image will continue to increase but through the majority of consumers with the Christian religion group, because it basically refers to the concept of cafes by utilizing religious beliefs related to the vision and mission of the café
\end{abstract}

Keywords: Blessed Brothers Cafe, Brand Image, Religious Attribute.

\begin{abstract}
Abstrak
Pada zaman sekarang, berbagai usaha bisnis yang dilakukan telah mengalami perkembangan yang luar biasa dari segi konsep dan pemasaran tentunya. Blessed Brothers Cafe sebagai kafe yang termasuk star up dengan mengusung konsep rohani terkait dengan agama Kristen serta melakukan pemanfaatan atribut agama sebagai bagian dekorasi untuk kafe tersebut. Blessed Brothers Cafe dalam mengembangkan bisnisnya tidak serta merta mencari keuntungan tetapi melalui visi dan misi mereka yang mengutamakan pelayanan dan pengalaman yang terbaik agar nama Tuhan Yesus ditinggikan serta menjadikan Blessed Brothers Cafe sebagai wadah dalam melakukan sharing bersama-sama alias penginjilan, menjadikan kafe tersebut termasuk ke dalam kategori unik dari segi konsep dan visi misi nya. Tujuan dari penelitian ini adalah untuk mengetahui brand image terhadap Blessed Brothers Cafe sebagai kafe star up yang unik berdasarkan konsep pemanfaatan atribut agama Kristen serta mengacu pada visi dan misi kafe tersebut. Teori yang digunakan dalam penelitian ini, mencakup jenis-jenis teori branding seperti teori brand image dan brand association serta teori atribut. Metode penelitian yang digunakan dalam penelitian ini adalah metode penelitian deskriptif kualitatif. Pengumpulan data dilakukan dengan cara wawancara, observasi, dan dokumentasi. Melalui hasil penelitian, peneliti menyimpulkan bahwa brand image Blessed Brothers Cafe akan terus meningkat tetapi melalui mayoritas konsumen dengan golongan agama Kristen, karena pada dasarnya mengacu pada konsep kafe dengan memanfaatkan aribut agama yang terkait juga melalui visi dan misi dari kafe tersebut.
\end{abstract}


Kata Kunci: Blessed Brothers Cafe, Brand Image, Atribut Agama.

\section{Pendahuluan}

Dalam perkembangan bisnis pada era millenial ini, suatu bisnis usaha selalu didukung dengan cara dan ide mereka sendiri. Melalui ide-ide kreatif yang dapat menarik daya tarik konsumen, suatu bisnis usaha dapat berkembang menjadi lebih baik juga tentunya mendapat keuntungan secara besar. Tentunya lokasi yang strategis, ide kreatif, visi, misi, dan usaha yang gigih dapat menjadikan suatu bisnis usaha dapat berkembang pesat sehingga mendapatkan apresiasi yang baik dari konsumen. Suatu bisnis usaha, baik yang telah berkembang pesat secara otomatis akan mendapatkan brand image yang popular di kalangan masyarakat. Bisnis usaha tersebut secara tidak langsung memiliki pandangan tersendiri atas brand image yang diletakkan terhadap bisnis usaha tersebut. Suatu bisnis usaha, baik yang telah berkembang pesat secara otomatis akan mendapatkan brand image yang popular di kalangan masyarakat. Bisnis usaha tersebut secara tidak langsung memiliki pandangan tersendiri atas brand image yang diletakkan terhadap bisnis usaha tersebut. Atas penjelasan dan teori tersebut, peneliti dalam penelitian ilmiahnya ini membahas Blessed Brothers Cafe yang memiliki brand image dengan pemanfaatan atribut agama yang dilihat dari dekorasi tempat kafe tersebut.

Blessed Brothers Cafe yang saat ini telah menjadi tempat baru untuk semua kalangan umur dalam menikmati produk mereka sendiri, saat ini sedang digandrungi para khalayak bukan hanya karena makanan nya saja melainkan karena brand image dari kafe tersebut yang punya paradigma dari sisi keagamaan dengan tempat yang strategis juga ditambah dengan pemanfaatan atribut yang sangat menonjol ke sisi agama. Dalam hal ini, manajemen pemasaran juga berperan penting dalam terciptanya brand image yang populer untuk Blessed Brothers Cafe, namun tidak terlalu signifikan dibahas karena peneliti disini lebih mengutamakan pembahasan tentang pemanfaatan atribut agama dari brand image yang terkait. Inilah yang dilakukan oleh peneliti dalam melakukan penelitian untuk membuktikan, bahwa pemanfaatan atribut agama terhadap brand image Blessed Brothers Cafe merupakan manajemen pemasaran yang tepat dalam menarik konsumen agar kafe tersebut dapat diingat di ingatan para konsumen melalui atribut-atribut agama yang kuat serta peneliti merujuk pada teori branding tentang brand image.

\section{Metode Penelitian}

Dalam penelitian ini, peneliti menggunakan penelitian kualitatif, dimana menurut Sugiyono (2011:15), "penelitian kualitatif adalah suatu proses penelitian dan pemahaman yang berdasarkan pada metodologi yang menyelidiki suatu fenomena sosial dan masalah manusia”.

Berdasarkan tujuan penelitian yang telah dijelaskan di atas, peneliti menggunakan penelitian kualitatif dengan pendekatan deskriptif. Pendekatan deskriptif menurut Ruben dan Stewart (2013:181), adalah "suatu pendekatan terhadap suatu perilaku, fenomena, peristiwa, masalah, atau keadaan tertentu yang menjadi suatu sebuah objek penelitian, yang kemudian hasil penelitiannya akan berupa uraian kalimat bermakna yang menjelaskan pemahaman tertentu”. 
Maka, peneliti dalam penelitian ini akan menjelaskan secara akurat, sistematis, dan faktual dari data atau informasi yang telah diperoleh lalu dideskripsikan sesuai dengan realita yang ada di lapangan dan diuraikan dalam bentuk kata-kata atau kalimat hingga akan mendapat suatu kesimpulan.

\section{Hasil Temuan dan Diskusi}

Blessed Brothers Cafe telah menjadi kafe yang mungkin pertama kalinya di Indonesia yang telah melakukan konsep pemasaran dan pendekatan dengan menggunakan atribut agama yang menonjol. Berdasarkan, yang peneliti dapatkan melalui hasil wawancara terhadap salah satu owner kafe tersebut, Jevier Justin, logo dari Blessed Brothers Cafe sangat mencerminkan atribut agama yang sangat menonjol ketika dilihat dan memiliki makna untuk logo tersebut yaitu, empat orang owner Blessed Brothers Cafe yang masing-masing menopang salib tersebut di keempat sisi. Blessed Brothers Cafe mempunyai visi yang berdasarkan filosofi penginjilan dalam ajaran Kekristenan serta misi mereka dalam menjadikan Blessed Brothers Cafe sebagai wadah dalam melakukan sharing bersama-sama alias penginjilan yang berarti memberitakan kabar baik tentang kebaikan Kristus dalam tiap hidup para Kristiani.

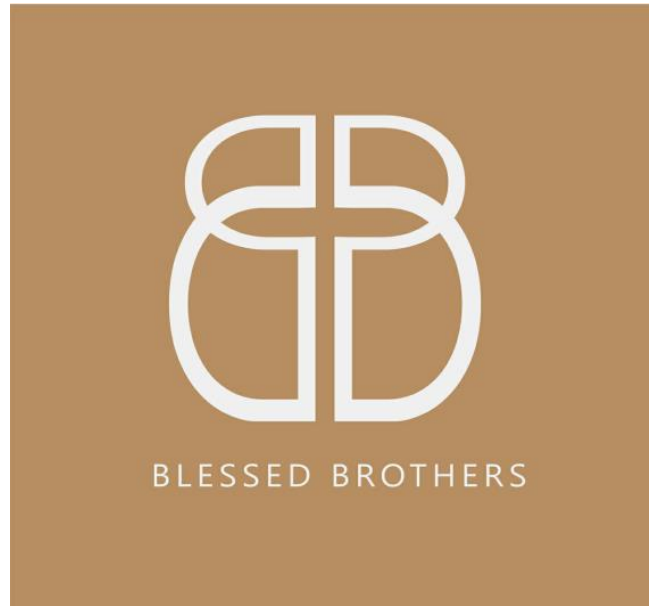

Gambar 1. Logo Brand Blessed Brothers Cafe Sumber: https://instagram.com/blessedbroscafe

Blessed Brothers Cafe sangat menjunjung tinggi nilai rohani yang terkandung dalam ajaran Kekristenan dan filosofi penginjilan yang mereka terapkan yang merupakan visi dari Blessed Brothers Cafe, menegaskan bahwa dalam setiap melakukan penginjilan, hendaknya memberi makan terlebih dahulu kepada setiap orang yang di mana seperti yang Tuhan Yesus juga lakukan kepada murid-muridnya dalam agama Kristen. Secara tidak langsung, brand image terhadap Blessed Brothers Cafe sendiri berdampak dari para konsumen nya sendiri yang sebagian besar memang beragama Kristen tetapi tidak menutupi untuk konsumen yang berbeda agama dalam mencoba makanan dan lain-lain karena di dasari oleh keingintahuan yang besar serta mencintai kuliner jenis apapun. 


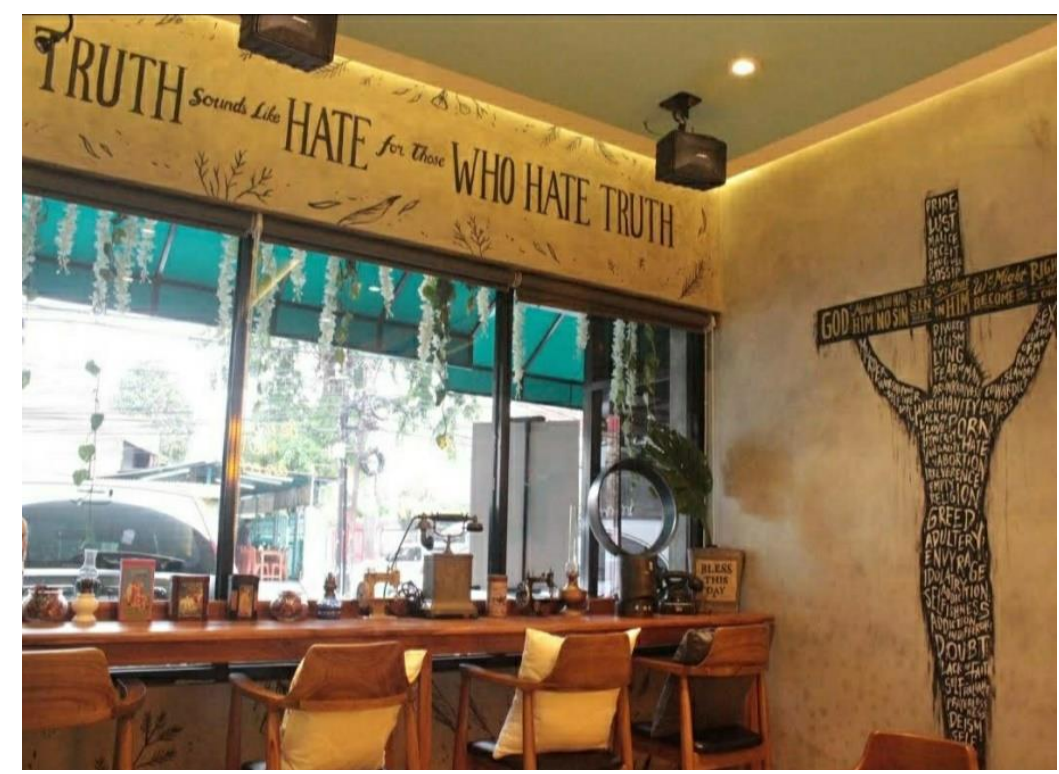

Gambar 2. Ruang Reservasi Blessed Brothers Café

Sumber: https://instagram.com/blessedbroscafe

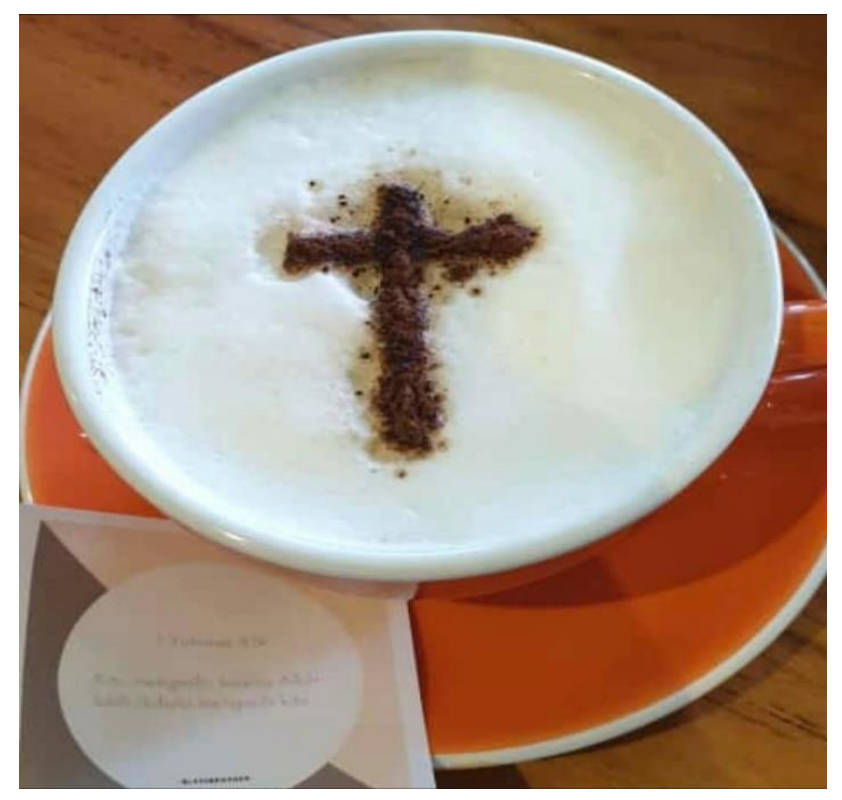

Gambar 3. Contoh Menu Kopi di BBC Sumber: Dokumentasi Pribadi

Pembahasan ini dapat diperkuat dengan sebuah pernyataan ketika mewawancarai narasumber keempat. Berdasarkan pernyataan dari narasumber keempat yang peneliti dapat melalui hasil wawancara yaitu Dosen Ekonomi Universitas Tarumanagara, Bapak Arifin Djakasaputra yakni, sebagai berikut "Kalau saya liat, pemanfaatan seperti itu memang bagus sekaligus juga dapat menjadi boomerang, kenapa? Karena pada orang-orang tertentu, gak pas buat mereka.. Jadi, nggk pas buat mereka berkunjung di kafe tersebut, yah kan.. Kalau saya yang fanatik, saya merasa 
ini nggk pas buat saya dan nggk mau berkunjung ke situ.. Nah, yang bagusnya adalah umat-umat yang sejalan dengan agama yang kamu pasang atributnya, itu akan datang ke kafe itu.. kira-kira seperti itu.. Jadi, kalau kita bicara secara umum, itu akan membuat yah.. kita jadi terkotak-kotak, terkelompok hanya untuk umat yang terkait dengan agama kafe itu sementara untuk umat yang lain, tentunya akan merasa aneh gitu.. Mereka merasa nggk pas deh..".

Melalui pernyataan tersebut, dapat dipahami dengan apa yang dijelaskan oleh Bapak Arifin Djakasaputra, bahwa dengan pemanfaatan atribut agama tersebut serta tekad dari Blessed Brothers Cafe yang berdasarkan visi dan misi mereka dalam menjadikan kafe tersebut sebagai tempat dalam memberikan pelayanan dan pengalaman terbaik kepada setiap konsumen agar nama Tuhan Yesus Kristus dapat ditinggikan serta wadah untuk saling memberitakan kabar baik tentang Kristus alias penginjilan, membuat adanya pengelompokkan atau golongan konsumen dengan mayoritas beragama yang sama ketika berkunjung di Blessed Brothers Cafe yaitu agama Kristen terkait dengan agama yang ditekuni oleh empat owner kafe tersebut.

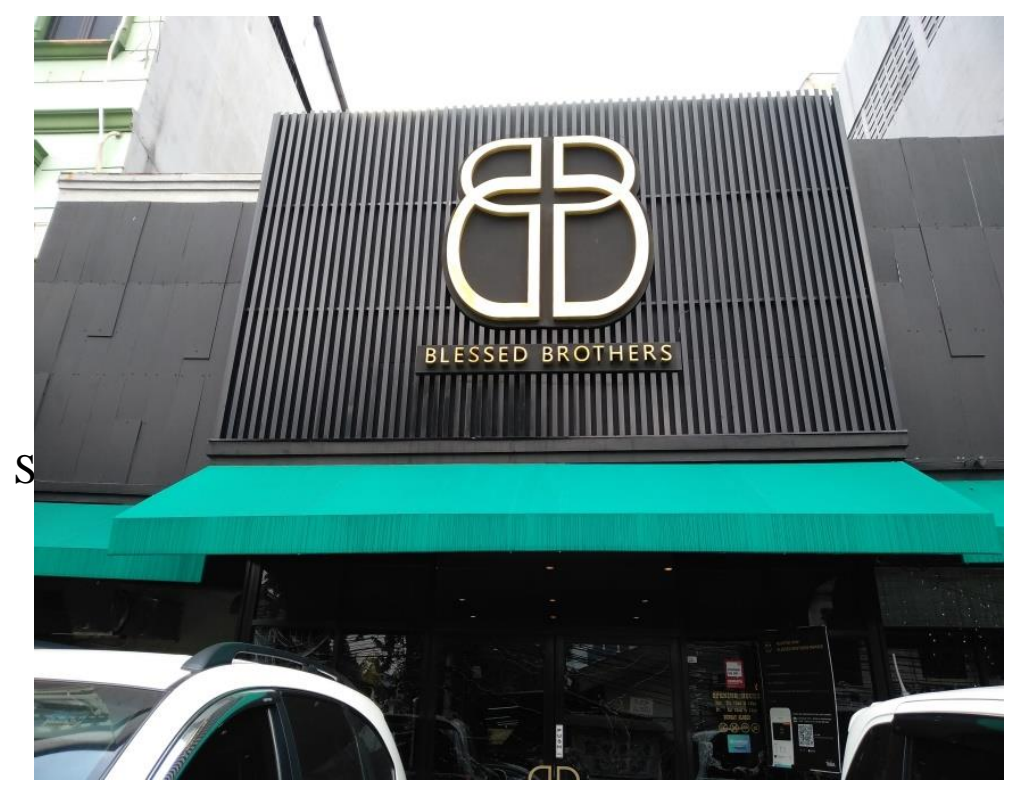

Gambar 4. Bagian Depan Blessed Brothers Café

Dalam pemahamannya, atribut dalam suatu produk adalah unsur yang menjadi pembeda atau pengembangan pada suatu produk agar dapat menambah nilai tambah, manfaat, dan juga menjadi bahan pertimbangan dalam melakukan pengambilan keputusan pembelian. Menurut Suharno dan Sutarso (2010:160), "atribut produk adalah pengembangan suatu produk perlu dilakukan dengan mendefinisikan manfaat yang akan ditawarkan, yang dikomunikasikan dan disampaikan melalui atribut produk, seperti kualitas, fitur, gaya, dan desain". 


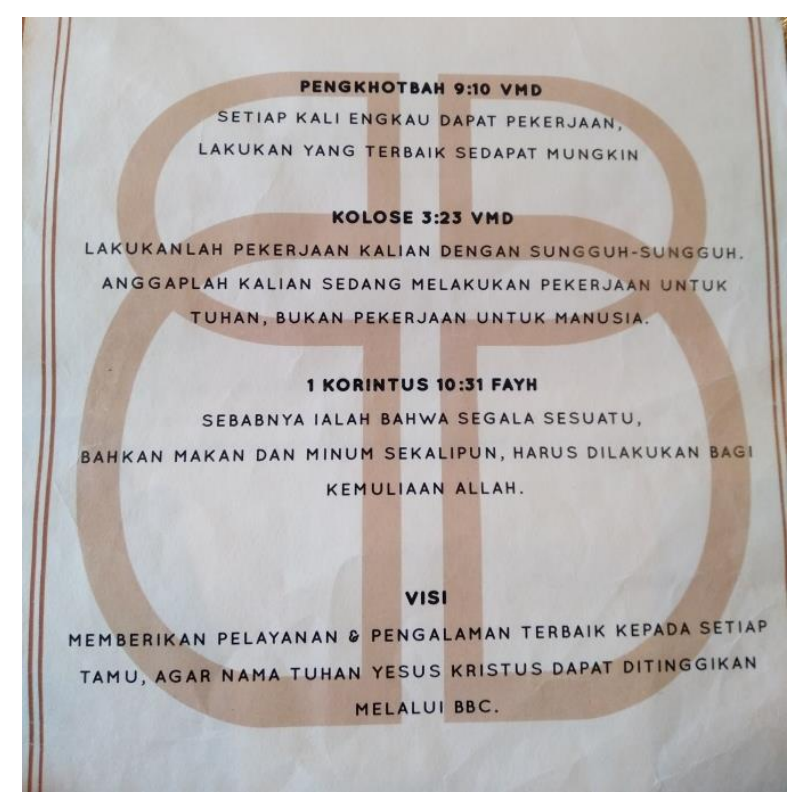

Gambar 5. Halaman Awal Buku Menu

\section{Sumber: Dokumentasi Pribadi}

Dalam penelitian ini, peneliti menitikberatkan pembahasan pada brand image, yang mana brand image sebagai persoalan utama yang dibahas oleh peneliti. Berdasarkan yang telah dijelaskan oleh peneliti di bab sebelumya, bahwa pengertian dari brand adalah "pemberian nama, istilah, tanda, simbol, rancangan, atau kombinasi dari kesemuanya yang dibuat dengan tujuan untuk mengidentifikasi barang atau jasa dan kelompok penjual untuk membedakan dari barang atau jasa pesaing". Kotler (2009). Sementara pengertian terhadap image (citra) menurut Kotler dan Keller (2012:274) adalah "cara masyarakat menganggap brand secara aktual".

Diketahui bahwa Blessed Brothers Cafe telah menjadi kafe pertama dengan aliran rohani Kristiani serta mengingat juga, brand Blessed Brothers Cafe telah ada di benak para konsumen bagi golongan mayoritas Kristiani tetapi juga tidak menghalangi konsumen yang berbeda agama untuk datang menikmati produk kuliner Blessed Brothers Cafe.

Sementara itu, teori brand association juga terkait dalam penelitian ini. Menurut Durianto (2001:6), "Brand association dapat mempengaruhi rasa percaya diri dari konsumen dalam pengambilan keputusan pembelian atas dasar pengalaman dalam penggunaan atau kedekatan asosiasi dengan berbagai karakteristik brand". Teori ini semakin diperkuat dengan adanya pemanfaatan atribut agama yang dilakukan Blessed Brothers Cafe yang berdampak kepada peningkatan jumlah konsumen dengan golongan agama Kristen yang berkunjung ke kafe tersebut. Mengingat juga bahwa, Blessed Brothers Cafe sangat berpegang teguh seturut dengan visi dan misi yang para owner Blessed Brothers Cafe jalankan untuk kafe tersebut berdasarkan ajaran agama Kristen. 
Gary Dwiputra Liawijaya, Ahmad Junaidi: Pemanfaatan Atribut Agama Terhadap Brand Image Blessed Brothers Café

\section{Simpulan}

Dalam hal dekorasi, Blessed Brothers Cafe telah menggunakan atribut agama yang terkait, yaitu agama Kristen serta logo Blessed Brothers Cafe sendiri yang mempunyai makna filosofi yang terkait dengan empat owner mereka.

Empat orang owner Blessed Brothers Cafe memiliki visi dan misi yang sama seturut dengan visi dan misi kafe tersebut, yaitu penginjilan. Penginjilan dalam ajaran Kekristenan adalah saling memberitakan kabar baik mengenai Tuhan Yesus Kristus satu sama lain dan bagi para owner Blessed Brothers Cafe sesuai visi mereka beserta kafe, dalam melakukan penginjilan hendaknya memberi makan dahulu kepada para konsumen. Dalam hal ini, melayani dan memberi makan yang terbaik untuk para konsumen merupakan prioritas utama Blessed Brothers Cafe sendiri yang dianggap sebagai wadah dalam melakukan penginjilan alias memuliakan nama Tuhan Yesus Kristus.

Hasil analisa peneliti terhadap dampak kualitas brand image Blessed Brothers Cafe adalah termasuk efektif, karena besar mayoritas konsumen Blessed Brothers Cafe adalah yang beragama Kristen, sesuai dengan agama pelopor kafe tersebut, yang otomatis membangun image tersendiri untuk Blessed Brothers Cafe serta kualitas brand mereka yang cepat diketahui banyak khalayak karena dianggap unik dan mungkin pertama kalinya di Indonesia sebagai kafe yang menggunakan konsep rohani dengan mempelopori agama Kristen serta memanfaatkan atribut agama mulai dari logo hingga dekorasi untuk kafe tersebut.

\section{Ucapan Terima Kasih}

Peneliti ingin berterima kasih kepada narasumber serta kerabat yang telah mendukung dalam penulisan penelitian ini baik secara materi maupun dukungan moril, terutama kepada Kak Jevier Justin dan Amelia Hermanto yang telah memberikan kesempatan serta meluangkan waktunya kepada peneliti untuk memperoleh informasi lengkap terkait penelitian tentang pemanfaatan atribut agama terhadap brand image Blessed Brothers Cafe. Melalui beliau peneliti memperoleh banyak pengetahuan baru pada bisnis start up yang terbilang unik dengan memanfaatkan keatributan agama. Terima kasih juga peneliti ucapkan pada Susanti serta Dosen Fakultas Ekonomi Universitas Tarumanagara, Bapak Arifin Djakasaputra, selaku pakar marketing komunikasi. Lalu, penulis berterima kasih kepada dosen pembimbing yaitu Bapak Ahmad Junaidi serta seluruh dosen dan staff Fakultas Ilmu Komunikasi Untar yang telah membantu proses penyelesaian penelitian ini. Tentunya semua masukan dari para narasumber dan dosen pembimbing sangat bermanfaat bagi peneliti dan berpengaruh besar terhadap perkembangan penelitian ini, terkait teori serta temuan peneliti. 


\section{Daftar Pustaka}

Sugiyono. (2011). Metode Penelitian Kuantitatif dan Kualitatif dan r\&d. Bandung: Alfabeta

Brent, D. Ruben dan Lea P. Stewart. (2013). Komunikasi dan Perilaku Manusia. Jakarta: PT RajaGrafindo Persada

Suharno dan Yudi Sutarso. (2010). Marketing In Practice. Yogyakarta: Graha Ilmu

Kotler, K. (2009). Manajemen Pemasaran 1.Edisi ketiga belas. Jakarta: Erlangga

Kotler, P. \& Keller, K.L. (2012). Manajemen Pemasaran Jilid I Edisi ke 12. Jakarta: Erlangga

Durianto, Sugiarto dan Tony Sitinjak. (2001). Strategi Menaklukan Pasar Melalui. Riset Ekuitas dan Perilaku Merek. PT. Gramedia Pustaka

Teguh, T. S., Rusdi, F., Pribadi, M. A. (2018). Perencanaan Komunikasi Pemasaran: Studi Kasus Tim Marketing Asuransi PT ASWATA. Prologia, 1(2), 198-202. Retrieved from https://journal.untar.ac.id/index.php/prologia/article/view/2392 